\title{
The Influence of Psychotropic Drugs on Investor Overconfidence
}

\author{
${\text { Marcia Zindel }{ }^{1} \text {, Gabriel Ribeiro' }{ }^{1} \text {, Carlos H. Rocha }{ }^{1}, \text { Sergio Da Silva2* }}^{*}$ \\ ${ }^{1}$ Department of Production Engineering, University of Brasilia, Brasilia, Brazil \\ ${ }^{2}$ Department of Economics, Federal University of Santa Catarina, Florianopolis, Brazil \\ Email: * professorsergiodasilva@gmail.com
}

How to cite this paper: Zindel, M., Ribeiro, G., Rocha, C.H. and Da Silva, S. (2019) The Influence of Psychotropic Drugs on Investor Overconfidence. Open Access Library Journal, 6: e5486.

https://doi.org/10.4236/oalib.1105486

Received: May 21, 2019

Accepted: June 2, 2019

Published: June 5, 2019

Copyright $\odot 2019$ by author(s) and Open Access Library Inc.

This work is licensed under the Creative Commons Attribution International License (CC BY 4.0).

http://creativecommons.org/licenses/by/4.0/

\begin{abstract}
We study the effects of the self-reported intake of stimulants, depressants and hallucinogens on investor overconfidence. A total of 105 investors participated. We find that the frequency of drug use did not affect overconfidence. However, overconfidence was correlated with the use of psychotropic drugs in our sample; regardless of type, we find a positive correlation of 15 percent. Correlation of investor overconfidence with stimulants in particular was even stronger at 41 percent. We suggest that identifying the ways psychotropic drugs in general, and stimulants in particular, interfere with striatum activity, is key for understanding their effects on investor overconfidence.
\end{abstract}

\section{Subject Areas}

Behavioral Economics, Medicine

\section{Keywords}

Psychotropic Drugs, Investor Overconfidence, Behavioral Economics

\section{Introduction}

Overconfidence is a psychological bias in which the subjective confidence in one's judgement is greater than the objective accuracy of the judgement. It is well established in the literature that entrepreneurs, managers and investors are overconfident [1]-[7]. Overconfident investors overestimate the precision of their own knowledge and skills. As a result, they are often more confident than right, and wrong when they are sure they are right [8]. Whenever investor confidence overcomes investor accuracy, financial markets overtrade and under-react to information [9], becoming more volatile [10]. Things are likely to become even worse when investors make decisions under the effect of psycho- 
tropic drugs [11].

Risk taking increases under the influence of alcohol [12], cannabis [13], and benzodiazepines (Valium [14]) and Alprazolam [15]. Amphetamines (such as Adderall) cause heightened focus and wakefulness, and this helps poker playing [16]. Propranolol, a beta blocker used to treat "stage fright" and other types of anxiety and impulsivity, reduces the discrimination between large and small possible losses when the probability of winning is low [17].

Perhaps one in four large investors has used some kind of mood-altering drug [18]. These also include Selective Serotonin Reuptake Inhibitors (SSRI) to treat depression: citalopram (Celexa), escitalopram (Lexapro), fluoxetine (Prozac), paroxetine (Paxil, Pexeva), sertraline (Zoloft) and vilazodone (Viibryd). Investors taking these drugs "report that they become far less cautious than they were before, worrying too little about real dangers" [18]. Citalopram decreases fear-related amygdala activations [19]. Prozac is known among executives as "teflon-medicine", because it allows them to look past perceived threats, decide quickly without ruminating and remain more optimistic during stress. Paxil does not cause euphoria for most people, but it can block fear and sadness, cause a reduction in threat perception and increase affiliative behaviors [20]. The characteristics of decreased threat perception and increased social affiliation mirror the decreased risk perception and herding of overly bullish investors [11]. Thus, SSRI are "steroids for the business Olympics" [21].

This work studies the effects of self-reported intake of stimulants, depressants and hallucinogens on investor overconfidence. Stimulants ("uppers") make one feel less tired both physically and mentally. Types of stimulants include amphetamines, methamphetamines, lisdexamfetamines, methylphenidates (Ritalin), MDMA (Ecstasy or Molly), cocaine, nicotine, caffeine and diet pills. Depressants (“downers") reduce arousal. Types include alcohol, barbiturates, benzodiazepines, cannabis, opioids, alpha and beta blockers (Propranolol), anticholinergics (Atropine), anticonvulsants (Pregabalin), antihistamines (Diphenhydramine), antipsychotics (Haloperidol), hypnotics (Zolpidem), muscle relaxants (Baclofen) and sedatives. Hallucinogens cause changes in thoughts, emotion and consciousness. Types include ayahuasca, psilocybin, mescaline and LSD. After reporting whether or not they consume any of these drugs, volunteers in our experiment indicate their frequency of use into three categories: mild (less than one time per week), moderate (two to three times per week) or heavy (daily).

The rest of this paper is organized as follows: Section 2 describes the materials and methods used; Section 3 shows the results found and Section 4 presents the conclusion.

\section{Materials and Methods}

We prepared a questionnaire to gauge overconfidence and another to assess the participants' consumption of drugs. We initially sent both Google Forms online to 48 consented volunteer students who had previous investment experience. 
The students were from the University of Brasilia, Brazil, and were enrolled in production engineering. We asked them to resend the link to acquaintances. Data collection started on 20 April 2017 and finished on 2 June 2017. In the end, a total of 105 investors participated (62 males; 62 were ages 25 and older; 29 had a college degree).

Participants freely reported their consumption of drugs and the frequency, as described earlier. Overconfidence can be easily assessed through a questionnaire, and we opted to employ the classical one [22]. The description of this questionnaire in detail is provided elsewhere [23]. After responding to a set of 10 true-false questions, respondents indicate how confident they were in the response given, either $50,60,70,80,90$ or 100 percent. A value of 50 percent means one respondent had no idea what the correct response was, because the same probability means a random guess between two choices. A value of 100 percent means the respondent was completely confident in the response. After subtracting how confident one respondent was in all the 10 questions from the correct responses given (in percentages), one gets a measure of overconfidence, in case of a resulting positive value.

\section{Results}

The average confidence level for all investors was 77.74 percent and their accuracy was 59.62 percent, meaning they were overconfident. Only 11 percent of the estimates of confidence coincided with the correct results. In general, the estimates of confidence were 29 percent higher than the correct responses.

Overconfidence occurs when the confidence judgments are larger than the relative frequencies of the correct responses, in which case there is poor calibration. Figure 1 shows a calibration curve [24], derived as follows: 1) we collected

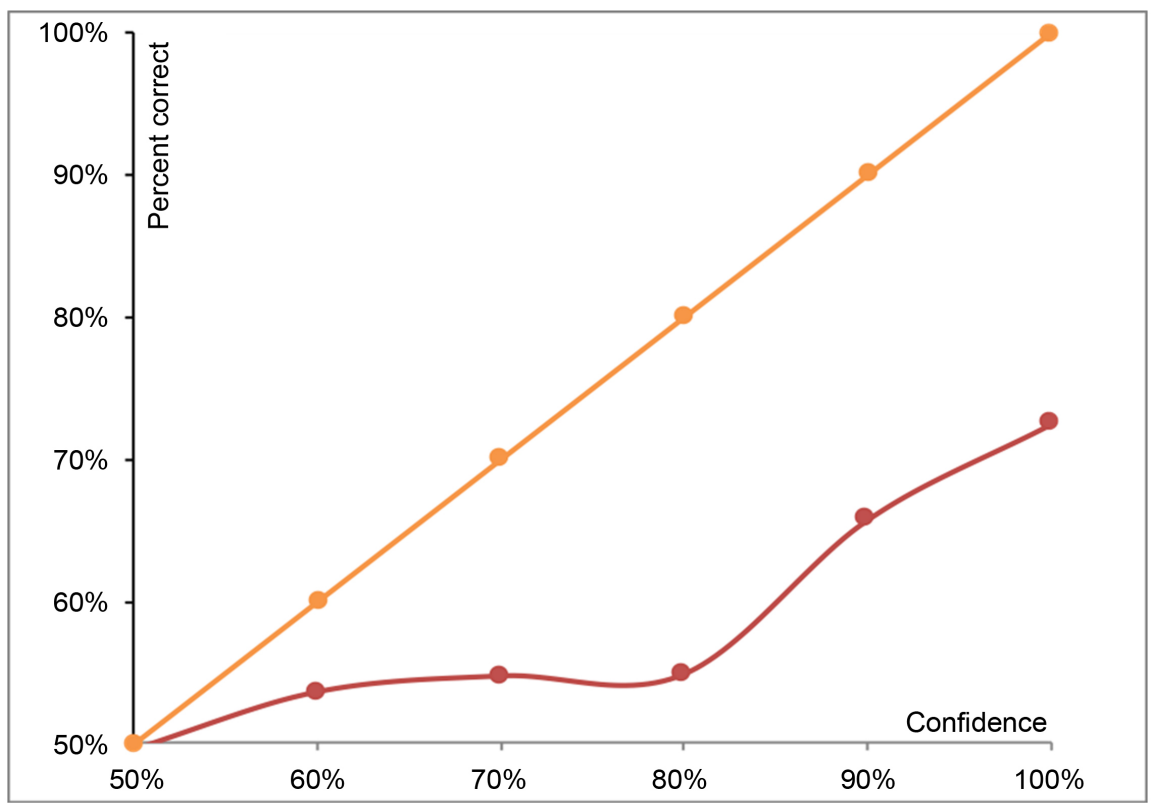

Figure 1. Calibration curve: overconfidence curve (in red) and the $45^{\circ}$ identity line. 
the probability assessments for each of the 10 items; 2) we grouped similar assessments within ranges (for example, all assessments between 0.60 and 0.69 were placed in the same category); 3) within each category, we computed the proportion that was correct (that is, the proportion of items for which the proposition was true or the alternative was correct); 4) for each category, we plotted the mean response (on the abscissa) against the proportion correct (on the ordinate). Perfect calibration would be shown by all points falling on the identity line. Figure 1 shows how the overconfidence effect appeared in our sample. Of note, the greatest excesses occurred for the confidence level of the 80 percent interval.

Table 1 shows the responses from the questionnaires in detail. The vast majority of the participants displayed overconfidence ( 88 percent). Only 12 showed underconfidence and a single one was perfectly calibrated. Only 36 participants were drug free. The majority in our sample (66 percent) used some type of drug. Hallucinogens (H) were consumed by 46 participants, stimulants (S) by 27 , and depressants (D) by 22 .

Five hallucinogen users displayed underconfidence, one was perfectly calibrated, and the vast majority showed a 33.5 percent average overconfidence. Five stimulant users showed underconfidence, and the majority showed a 32.3 percent average overconfidence. Two depressant users displayed underconfidence, and the majority showed a 37.4 percent average overconfidence.

As for the frequency of consumption, it was mild for 33 users, moderate for 24 and heavy for 13. Of note, whenever one participant indicated a moderate use of hallucinogens and a high consumption of stimulants, for example, her frequency of consumption was classified as heavy. For those heavy users, two showed underconfidence; the others showed a 32 percent average overconfidence. For mild users, seven displayed underconfidence; the others presented the same 32 percent average overconfidence as that of heavy users. So, the frequency of consumption did not seem to matter for overconfidence in our sample.

However, overconfidence was correlated with the consumption of drugs in our study, regardless of type (for all drugs, Pearson's coefficient $=0.152$, $\chi^{2}(2)=1.58, p<0.05$; critical value $=1.38$ ). Despite this low positive correlation of 15 percent, correlation with stimulants in particular was stronger. That is, 41 percent (for stimulants, Pearson's coefficient $=0.414, \chi^{2}(2)=3.31, p<0.05$; critical value $=3.22$ ). Nevertheless, correlations with the other types of drugs were non-significant in our sample: the chi-square statistics fell below the critical values (for depressants, Pearson's coefficient $=0.422, \chi^{2}(2)=4.34, p<0.05$; critical value $=4.61$; for hallucinogens, Pearson's coefficient $=0.119$, $\chi^{2}(2)=.664, p<0.05$; critical value $\left.=0.713\right)$.

These results make sense from a neuroscience perspective. The more confident people are about their performance, the higher the activation in brain areas such as the striatum, which is a region often associated with reward processing [25]. However, too much confidence is associated with lower metacognitive ability [25]. When combined, such results indicate that although being confident 
M. Zindel et al.

Table 1. Questionnaires responses.

\begin{tabular}{|c|c|c|c|}
\hline Participant & Confidence, \% & Drug type & Frequency of use \\
\hline 1 & 45 & $\mathrm{H}$ & Mild \\
\hline 2 & 50 & $\mathrm{H}$ & Mild \\
\hline 3 & 3 & $\mathrm{H}$ & Moderate \\
\hline 4 & -15 & $\mathrm{H}$ & Moderate \\
\hline 5 & 24 & $\mathrm{H}$ & Heavy \\
\hline 6 & 46 & $\mathrm{H}, \mathrm{S}$ & Heavy \\
\hline 7 & 0 & $\mathrm{H}$ & Moderate \\
\hline 8 & 41 & $\mathrm{H}, \mathrm{S}$ & Moderate \\
\hline 9 & 33 & $\mathrm{H}$ & Moderate \\
\hline 10 & 1 & $\mathrm{H}, \mathrm{S}$ & Heavy \\
\hline 11 & 49 & $\mathrm{H}$ & Heavy \\
\hline 12 & 32 & $\mathrm{H}$ & Heavy \\
\hline 13 & 45 & $\mathrm{H}$ & Heavy \\
\hline 14 & 18 & $\mathrm{H}, \mathrm{S}$ & Moderate \\
\hline 15 & 66 & $\mathrm{H}, \mathrm{S}, \mathrm{D}$ & Heavy \\
\hline 16 & 29 & $\mathrm{H}$ & Heavy \\
\hline 17 & 47 & S, D & Moderate \\
\hline 18 & 14 & $\mathrm{H}, \mathrm{S}, \mathrm{D}$ & Moderate \\
\hline 19 & 80 & & Moderate \\
\hline 20 & 55 & H, S, D & Moderate \\
\hline 21 & 54 & $\mathrm{H}, \mathrm{D}$ & Moderate \\
\hline 22 & 50 & $\mathrm{H}, \mathrm{S}$ & Moderate \\
\hline 23 & 44 & $\mathrm{H}, \mathrm{D}$ & Moderate \\
\hline 24 & 24 & & \\
\hline 25 & 36 & $\mathrm{H}$ & Mild \\
\hline 26 & 30 & $\mathrm{D}$ & Mild \\
\hline 27 & 28 & & \\
\hline 28 & 9 & & \\
\hline 29 & 23 & & \\
\hline 30 & 41 & $\mathrm{H}, \mathrm{S}$ & Mild \\
\hline 31 & 26 & $\mathrm{D}$ & Moderate \\
\hline 32 & 38 & $\mathrm{H}$ & Mild \\
\hline 33 & 33 & & \\
\hline 34 & 47 & & \\
\hline 35 & 31 & & \\
\hline 36 & 26 & $\mathrm{D}$ & Mild \\
\hline 37 & 33 & $\mathrm{D}$ & Mild \\
\hline 38 & 31 & & \\
\hline 39 & 30 & & \\
\hline
\end{tabular}




\section{Continued}

\begin{tabular}{|c|c|c|c|}
\hline 40 & 33 & & \\
\hline 41 & 13 & & \\
\hline 42 & 15 & & \\
\hline 43 & 29 & $\mathrm{D}$ & Mild \\
\hline 44 & 19 & $\mathrm{H}, \mathrm{S}$ & Mild \\
\hline 45 & 14 & & \\
\hline 46 & 32 & $\mathrm{D}$ & Mild \\
\hline 47 & 16 & & \\
\hline 48 & 25 & & \\
\hline 49 & 46 & $\mathrm{H}, \mathrm{S}$ & Mild \\
\hline 50 & 39 & $S$ & Mild \\
\hline 51 & 35 & S, D & Moderate \\
\hline 52 & 38 & S, D & Mild \\
\hline 53 & 39 & $\mathrm{H}, \mathrm{S}$ & Moderate \\
\hline 54 & 33 & $S$ & Moderate \\
\hline 55 & 24 & & \\
\hline 56 & 36 & $\mathrm{H}, \mathrm{S}$ & Moderate \\
\hline 57 & 33 & $\mathrm{D}$ & Mild \\
\hline 58 & 53 & $\mathrm{D}$ & Mild \\
\hline 59 & 38 & $\mathrm{D}$ & Mild \\
\hline 60 & 53 & $\mathrm{H}$ & Mild \\
\hline 61 & 43 & $\mathrm{H}$ & Heavy \\
\hline 62 & 17 & $\mathrm{D}$ & Moderate \\
\hline 63 & 20 & & \\
\hline 64 & 36 & $\mathrm{H}, \mathrm{D}$ & Mild \\
\hline 65 & 36 & & \\
\hline 66 & 42 & $\mathrm{H}, \mathrm{D}$ & Moderate \\
\hline 67 & 45 & & \\
\hline 68 & 25 & & \\
\hline 69 & 32 & & \\
\hline 70 & 42 & & \\
\hline 71 & 22 & & \\
\hline 72 & 14 & & \\
\hline 73 & 12 & & \\
\hline 74 & 18 & $\mathrm{H}$ & Moderate \\
\hline 75 & 6 & $\mathrm{H}$ & Mild \\
\hline 76 & 8 & & \\
\hline 77 & 38 & $\mathrm{H}$ & Mild \\
\hline 78 & 62 & $\mathrm{H}$ & Moderate \\
\hline 79 & 31 & & \\
\hline 80 & 50 & & \\
\hline
\end{tabular}




\section{Continued}

\begin{tabular}{|c|c|c|c|}
\hline 81 & 37 & $\mathrm{H}$ & Mild \\
\hline 82 & 12 & & \\
\hline 83 & -30 & $\mathrm{H}$ & Mild \\
\hline 84 & 4 & $\mathrm{H}$ & Mild \\
\hline 85 & 55 & & \\
\hline 86 & -20 & $\mathrm{H}$ & Moderate \\
\hline 87 & 18 & & \\
\hline 88 & -14 & $\mathrm{D}$ & Mild \\
\hline 89 & -9 & S & Mild \\
\hline 90 & 1 & & \\
\hline 91 & 32 & & \\
\hline 92 & -7 & $\mathrm{D}$ & Heavy \\
\hline 93 & -26 & & \\
\hline 94 & 18 & $\mathrm{H}$ & Mild \\
\hline 95 & -10 & $\mathrm{H}$ & Heavy \\
\hline 96 & -19 & $\mathrm{H}, \mathrm{S}$ & Mild \\
\hline 97 & 17 & S & Mild \\
\hline 98 & -11 & S & Mild \\
\hline 99 & 2 & $\mathrm{H}, \mathrm{S}$ & Heavy \\
\hline 100 & 16 & $\mathrm{H}$ & Heavy \\
\hline 101 & 17 & S & Moderate \\
\hline 102 & -4 & S & Mild \\
\hline 103 & 3 & & \\
\hline 104 & -10 & $S$ & Mild \\
\hline 105 & 11 & $\mathrm{H}, \mathrm{S}$ & Mild \\
\hline
\end{tabular}

entails a reward-like component, it can also lead to overconfidence. Therefore, identifying the ways psychotropic drugs in general, and stimulants in particular, interfere with striatum activity is key for understanding their effects on investor overconfidence.

\section{Conclusion}

We study the effects of self-reported intake of stimulants, depressants and hallucinogens on investor overconfidence using a sample of 105 participants. First, we replicate the well-established overconfidence effect in our own experiment, thus finding an average level of confidence for all investors of 77.74 percent, along with an accuracy level of 59.62 percent. Then, we find a positive correlation of 15 percent between overconfidence and the use of psychotropic drugs in our sample, regardless of type. In particular, the correlation of investor overconfidence with stimulants only is even stronger at 41 percent, but correlations with the other types of drugs are non-significant. Nevertheless, we find the frequency of 
drug consumption not to matter for overconfidence in our sample. We suggest that identifying the ways psychotropic drugs in general, and stimulants in particular, interfere with striatum activity, is key for understanding their effects on investor overconfidence.

\section{Acknowledgements}

Financial support from CNPq and Capes is acknowledged.

\section{Conflicts of Interest}

The authors declare no conflicts of interest regarding the publication of this paper.

\section{References}

[1] Cooper, A.C., Woo, C.A. and Dunkelberg, W. (1988) Entrepreneurs Perceived Chances for Success. Journal of Business Venturing, 3, 97-108. https://doi.org/10.1016/0883-9026(88)90020-1

[2] Busenitz, L.W. and Barney, J.B. (1997) Differences between Entrepreneurs and Managers in Large Organizations: Biases and Heuristics in Strategic Decision-Making. Journal of Business Venturing, 12, 9-30. https://doi.org/10.1016/S0883-9026(96)00003-1

[3] Delong, B.J., Shleifer, A., Summers, L. and Waldmann, R.J. (1991) The Survival of Noise Traders in Financial Markets. Journal of Business, 64, 1-20.

https://www.jstor.org/stable/2353070 https://doi.org/10.1086/296523

[4] Daniel, K., Hirshleifer, D. and Subrahmanyam, A. (1998) Investor Psychology and Security Market Under- and Over-Reactions. Journal of Finance, 53, 1839-1886. https://www.jstor.org/stable/117455 https://doi.org/10.1111/0022-1082.00077

[5] Odean, T. (1998) Volume, Volatility, Price and Profit When All Traders Are above Average. Journal of Finance, 53, 1887-1934. https://doi.org/10.1111/0022-1082.00078

[6] Bernardo, A.E. and Welch, I. (2001) On the Evolution of Overconfidence and Entrepreneurs. Journal of Economics \& Management Strategy, 10, 301-330. https://doi.org/10.1111/j.1430-9134.2001.00301.x

[7] Grinblatt, M. and Keloharju, M. (2009) Sensation Seeking, Overconfidence, and Trading Activity. Journal of Finance, 64, 549-578. https://doi.org/10.1111/j.1540-6261.2009.01443.x

[8] Fischhoff, B., Slovic, P. and Lichtenstein, S. (1977) Knowing with Certainty: The Appropriateness of Extreme Confidence. Journal of Experimental Psychology, 3, 552-564. https://doi.org/10.1037/0096-1523.3.4.552

[9] Kim, O. and Verrecchia, R.E. (1991) Market Reaction to Anticipated Announcements. Journal of Financial Economics, 30, 273-309. https://doi.org/10.1016/0304-405X(91)90033-G

[10] Benos, A.V. (1998) Aggressiveness and Survival of Overconfident Traders. Journal of Financial Markets, 1, 353-383. https://doi.org/10.1016/S1386-4181(97)00010-4

[11] Peterson, R.L. (2007) Affect and Financial Decision-Making: How Neuroscience Can Inform Market Participants. Journal of Behavioral Finance, 8, 70-78. 
https://doi.org/10.1080/15427560701377448

[12] Lane, S.D., Cherek, D.R., Pietras, C.J. and Tcheremissine, O.V. (2004) Alcohol Effects on Human Risk Taking. Psychopharmacology, 172, 68-77.

https://doi.org/10.1007/s00213-003-1628-2

[13] Lane, S.D., Cherek, D.R., Tcheremissine, O.V., Lieving, L.M. and Pietras, C.J. (2005) Acute Marijuana Effects on Human Risk Taking. Neuropsychopharmacology, 30, 800-809. https://doi.org/10.1038/sj.npp.1300620

[14] Deakin, J.B., Aitken, M.R., Dowson, J.H., Robbins, T.W. and Sahakian, B.J. (2004) Diazepam Produces Disinhibitory Cognitive Effects in Male Volunteers. Psychopharmacology, 173, 88-97. https://doi.org/10.1007/s00213-003-1695-4

[15] Lane, S.D., Tcheremissine, O.V., Lieving, L.M., Nouvion, S. and Cherek, D.R. (2005) Acute Effects of Alprazolam on Risky Decision Making in Humans. Psychopharmacology, 181, 364-373. https://doi.org/10.1007/s00213-005-2265-8

[16] Knutson, B., Bjork, J.M., Fong, G.W., Hommer, D.W., Mattay, V.S. and Weinberger, D.R.R. (2004) Amphetamine Modulates Human Incentive Processing. Neuron, 43, 261-269. https://doi.org/10.1016/j.neuron.2004.06.030

[17] Rogers, R.D., Lancaster, M., Wakeley, J. and Bhagwagar, Z. (2004) Effects of Beta-Adrenoceptor Blockade on Components of Human Decision-Making. Psychopharmacology, 172, 157-164. https://doi.org/10.1007/s00213-003-1641-5

[18] Nesse, R. (2000) Is the Market on Prozac? https://www.edge.org/response-detail/10609

[19] Del-Ben, C.M., Deakin, J.F., McKie, S., Delvai, N.A., Williams, S.R., Elliott, R., Dolan, M. and Anderson, I.M. (2005) The Effect of Citalopram Pretreatment on Neuronal Responses to Neuropsychological Tasks in Normal Volunteers: An fMRI Study. Neuropsychopharmacology, 30, 1724-1734.

https://doi.org/10.1038/sj.npp.1300728

[20] Knutson, B., Wolkowitz, O.M., Cole, S.W., Chan, T., Moore, E.A., Johnson, R.C., Terpstra, J., Turner, R.A. and Reus, V.I. (1998) Selective Alteration of Personality and Social Behavior by Serotonergic Intervention. American Journal of Psychiatry, 155, 373-379. https://doi.org/10.1176/ajp.155.3.373

[21] Kramer, P.D. (1993) Listening to Prozac: A Psychiatrist Explores Antidepressant Drugs and the Remaking of the Self. Viking, New York.

[22] Lichtenstein, S. and Fischhoff, B. (1977) Do Those Who Know More Also Know More about They Know? Organizational Behavior and Human Performance, 20, 159-183. https://doi.org/10.1016/0030-5073(77)90001-0

[23] Zindel, M.L., Menezes, E., Matsushita, R. and Da Silva, S. (2010) Biological Characteristics Modulating Investor Overconfidence. Economics Bulletin, 30, 1496-1508. http://www.accessecon.com/Pubs/EB/2010/Volume30/EB-10-V30-I2-P137.pdf

[24] Lichtenstein, S., Fischhoff, B. and Phillips, L.D. (1982) Calibration of Probabilities: The State of the Art to 1980. In: Kahneman, D., Slovic, P. and Tversky, A., Eds., Judgment under Uncertainty: Heuristics and Biases, Cambridge University Press, Cambridge, 306-334. https://doi.org/10.1017/CBO9780511809477.023

[25] Molenberghs, P., Trautwein, F.M., Bockler, A., Singer, T. and Kanske, P. (2016) Neural Correlates of Metacognitive Ability and of Feeling Confident: A Large-Scale fMRI Study. Social, Cognitive and Affective Neuroscience, 11, 1942-1951. https://doi.org/10.1093/scan/nsw093 